\title{
ESTRATÉGIA INSTITUCIONAL: RELAÇÃO ENTRE O PDI, PPI E PLANEJAMENTO ESTRATÉGICO NO IFB ${ }^{1}$
}

\author{
ESTRATEGIA CORPORATIVA: RELACIÓN ENTRE EL PDI, EL PPI Y \\ PLANIFICACIÓN ESTRATÉGICA EN IFB
}

\section{CORPORATE STRATEGY: RELATIONSHIP BETWEEN THE IDP, IEP AND PLANNING STRATEGIC IN IFB}

\author{
Pedro Henrique Rodrigues de Camargo DIAS ${ }^{2}$ \\ Jonilto Costa SOUSA ${ }^{3}$ \\ Cecília Cândida Frazão VIEIRA ${ }^{4}$
}

RESUMO: O presente estudo tem por objetivo identificar e caracterizar a relação do Plano de Desenvolvimento Institucional- PDI -, Projeto Pedagógico Institucional - PPI -, e o Planejamento Estratégico, especificamente no âmbito da eficácia organizacional. O PDI, PPI e Planejamento estratégico no Instituição Federal de Brasília - IFB -, se inter-relacionam, interagem em decorrência de sua natureza estratégica como foco nos resultados organizacionais. $\mathrm{O}$ estudo de abordagem qualitativa, de natureza aplicada e caráter exploratório, é instrumentalizado pela técnica documental e entrevistas semiestruturada, bem como análise de conteúdo. Os resultados evidenciaram que a integração eficiente entre PDI, PPI e Planejamento Estratégico, além de comunicar a missão, objetivos e metas institucionais, corroboram na construção de uma instituição de referência com a educação de qualidade, afirmando sua função social, orientando a ação dos servidores e gestores.

PALAVRAS-CHAVE: Plano de desenvolvimento institucional. Projeto pedagógico institucional. Planejamento estratégico. Estratégia. Resultado.

RESUMEN: Este estudio tiene como objetivo identificar y caracterizar la relación del Plan de Desarrollo Institucional - PDI - Proyecto Educativo Institucional - EPO - y la planificación estratégica, específicamente en el contexto de la eficacia de la organización. IDP, IEP y Planificación Estratégica en el Instituto Federal de Brasilia (Instituto Federal de Brasilia IFB) se interrelacionan e interactúan debido a su carácter estratégico y se centran en los resultados organizacionales. El estudio cualitativo de carácter exploratorio y personalidad aplicada, se instrumentaliza

1 Texto revisado e ampliado. Pesquisa apresentada na $1^{\circ}$ Jornada Ibero-Americana de Pesquisas em Políticas Educacionais e Experiências Interdisciplinares na Educação.

${ }^{2}$ Mestre em Gestão Pública pela Universidade de Brasília. Analista de Planejamento e Orçamento no Ministério Público Federal. E-mail: pedrohcamargo@ hotmail.com

${ }^{3}$ Universidade de Brasília (UnB). Professor Ajunto da UnB. Doutor em Administração. E-mail: jonilto@hotmail.com

${ }^{4}$ Universidade de Brasília (UnB). Mestranda em Educação. Pedagoga no Instituto Federal de Brasília. Email: cecilia.vieira@ifb.edu.br 
mediante técnicas documentales y entrevistas semiestructuradas y análisis de contenido. Los resultados mostraron Que la integración eficiente de IDP, IEP y Planificación Estratégica, y también se comunican la misión, objetivos y metas institucionales, corroborar la construcción de una institución de referencia con la calidad de la educación, indicando su función social, orientar la acción de los servidores y gerentes.

PALAVRAS CLAVE: Plan de desarrollo Institucional. Proyecto educativo Institucional. Planificación estratégica. Estratégia. Resultado.

ABSTRACT: This study aims to identify and characterize the relationship of the Institutional Development Plan - IDP -, Institutional Educational Project - IEP, - and the strategic planning, specifically in the context of organizational effectiveness. IDP, IEP and Strategic Planning at the Federal Institution of Brasilia (Instituto Federal de Brasilia IFB) interrelate and interact due to its strategic nature and focus on organizational results. The qualitative study of applied nature and exploratory personality, is instrumentalized by documentary techniques and semi-structured interviews and content analysis. The results showed that the efficient integration of IDP, IEP and Strategic Planning, and also communicate the mission, objectives and institutional goals, corroborate the construction of a reference institution with the quality of education, stating its social function, guiding the action of servers and managers.

KEYWORDS: Institutional development plan. Institutional educational Project. Strategic planning. Strategy. Result.

\section{Introdução}

As Instituições de Ensino Superior - IES - são consideradas uma das mais complexas organizações da sociedade contemporânea (MEYER JR., 2005; ARAÚJO, 1996), sensíveis às mudanças do ambiente que definem e organizam planos e desenvolvem estratégias de forma a ajustar sua capacidade a uma nova realidade frente às demandas.

A Estratégia organizacional é orientada por meio de definição de missão. Dessa forma, no art. 03, inciso I, a Lei n 10.861 de 2004 orienta que as IES elaborem o Plano de Desenvolvimento Institucional - PDI - que se constitui um orientador das ações dos gestores, de modo a atingir os resultados esperados e superar mudanças e contingências institucionais. Os autores Mizael et al. (2013) apontam que o PDI deve ser elaborado para um período de cinco anos e tem caráter normativo, assim, apresenta a missão, objetivos, metas, ações e prazos a serem alcançados. 
Para Dal Magro e Rausch (2012, p. 433), “com a revisão da Lei n 9.394/96 Lei de Diretrizes e Bases da Educação Nacional foi constatada a necessidade de implementar, no processo de avaliação das Instituições de Ensino Superior o planejamento estratégico, denominando de Plano de Desenvolvimento Institucional PDI", com isso, o PDI é integrado ao planejamento estratégico da organização.

Neste contexto, destaca-se que a implementação de um planejamento estratégico, tanto em organização pública como privada, não consiste em tarefa simples, porquanto, devem ser considerados os diversos contextos que as envolvem, afirma Matias-Pereira (2010). Dessa forma, as organizações estão inseridas em um ambiente competitivo e mutável, que forçam, necessariamente, uma alteração no modo de pensar e gerenciar seus processos, de tal modo a maximizar os resultados, uma vez que os processos de planejamento vagam em rumos diversos e não chegam aos resultados esperados.

Enquanto que, o Projeto Pedagógico Institucional - PPI, que também compõe o processo de regulação da Ensino Superior, constitui-se num instrumento político, filosófico e teórico-metodológico que "norteará as práticas acadêmicas da IES, tendo em vista sua trajetória histórica, inserção regional, vocação, missão, visão e objetivos gerais e específicos", conforme informa no documento de Diretrizes e Instrumento de Avaliação Externa (BRASIL, 2006, p. 35).

Portanto, esse estudo tem por objetivo identificar e caracterizar a relação que se apresenta entre o PDI, PPI e Planejamento Estratégico para alcance dos resultados organizacionais, observando o contexto complexo que os envolve e a dinâmica no Instituto Federal de Brasília - IFB.

A metodologia de pesquisa aplicada neste estudo, partiu de uma abordagem qualitativa, originada de produto de dissertação de mestrado, natureza aplicada. Desse estudo, evidenciou a categoria "Relação entre PDI, PPI e Planejamento estratégico" que estão intrinsecamente integrados ao processo metodológico de planejamento institucional. Além disso, em relação aos objetivos é exploratória ao passo que foi escolhido para estudo sobre o tema o Instituto Federal de Brasília - IFB como lócus.

A escolha do IFB para o estudo de caso justifica-se por este é uma instituição que compõe a Rede Federal de Educação Profissional e Tecnológica voltada para o ensino, pesquisa e extensão no âmbito da educação profissional e tecnológica, desde a educação básica ao ensino superior, também dedicada à formação de professores para a rede pública de educação básica que assumem valor estratégico no desenvolvimento 
nacional, visando atender aos mais diferenciados públicos na modalidade presencial e também a distância.

Ao passo que a intencionalidade dessa escolha é que os Institutos Federais, em seu cotidiano escolar têm que observar tanto a legislação da educação básica quanto a legislação do ensino superior e conciliar os diferentes aspectos que esses níveis da educação exigem. Sendo um dos principais meios para isso é utilizar seus norteadores: PDI, PPI e Planejamento Estratégico.

O estudo apoia-se nas técnicas de pesquisa bibliográfica, quanto aos meios, de forma a construir um embasamento teórico. Quanto aos fins, na técnica documental aliada à entrevista individual semiestruturada como procedimento de levantamento e coleta de dados, por conseguinte, na análise dos dados, a técnica análise de conteúdo.

Para as entrevistas, os participantes foram selecionados e delimitados os servidores com perfil de gestores estratégicos e táticos da instituição, responsáveis por implementar o Planejamento Estratégico, sendo eles: Reitor, Pró-Reitores, Diretores Gerais e Diretores de Administração e Planejamento. Posteriormente, a partir da percepção da fala de entrevistados e observações in loco, foram convidados os gestores responsáveis de três setores táticos correlatos: a Diretoria de Administração, Diretoria de Orçamento e a equipe da Coordenação Geral de Planejamento.

No total, foram realizadas trinta e três entrevistas, aplicadas no contexto de cada participante, e percorreu um período de duração de cinco meses, no ano de 2016. A aplicação do roteiro de entrevista permitiu produzir dados primários no sentido de identificar e caracterizar o processo de implementação do Planejamento Estratégico, e, por conseguinte a relação entre o PDI, PPI e Planejamento Estratégico, a partir da percepção dos atores, por meio de perguntas abertas. As entrevistas foram gravadas, após autorização, por equipamento próprio e transcritas para posterior análise de conteúdo, utilizando os procedimento e orientações de (CRESWELL, 2007).

As entrevistas transcritas se mostraram material de suma importância para posterior análise de conteúdo. Em média, cada entrevista teve duração de trinta minutos. Como extremos, algumas percorreram perto de uma hora e vinte e três minutos, ao passo que a de menor duração onze minutos. Ao final da coleta de dados, por meio de entrevistas, o pesquisador contava com cerca de dezessete horas de gravações em áudio para posterior transcrição. Para guardar o sigilo e privacidade dos entrevistados, neste texto, cada respondente foi categorizado com a inicial da letra "E" seguido de numeral. 
Quanto à análise de dados na construção e classificação de categorias observou a semântica, as semelhanças e diferenças entre enunciados, produzindo comparações, descrições e interpretações de forma a produzir inferências, subsidiadas pela literatura. Para isso, foram selecionados os dados documentais e verbalizações para a compreensão do entendimento institucional sobre seus norteadores estratégicos e a relação entre esses.

\section{Na educação superior o Plano de Desenvolvimento Institucional é intrínseco ao Planejamento Estratégico}

O planejamento não pode ser uma peça imutável para administração, mas sim, um instrumento útil, de forma a ser revisado periodicamente, sempre que revelar mudanças importantes nas condições externas e internas que afetam a instituição, permitindo a continuação ou adequação da instituição à alteração de cenários (FORPLAD, 1995).

É no planejamento estratégico da instituição que são definidos os objetivos estratégicos da organização, realizado a análise de ameaças e oportunidades do ambiente externo, os pontos fortes e fragilidades do ambiente interno, bem como, são definidos os referenciais estratégicos, tais como: missão, visão e valores, metas e ações da organização.

No Instituto Federal de Brasília o Planejamento Estratégico, conforme seu PDI, utilizou-se da metodologia de Balanced Scorecard com adaptações e destaca que para o período de 2014 a 2018 uma novidade incorporada ao processo foi sua construção participativa. Nesse sentido Falkembach (2010, p. 136) afirma que "essa mudança de atitude se constitui num avanço no sentido da maturação dos indivíduos e de seus processos organizativos bem como no sentido de recuperar e construir identidades".

Neste contexto, e de acordo com o entrevistado E-06 afirma que "O planejamento é algo fundamental, é a base para que nós possamos atingir alguma meta que foi previamente estabelecida, no sentido de organizar e sistematizar todas as etapas, que visam à busca desse objetivo no departamento".

Por sua vez, na entrevista de E-17 evidencia as etapas do planejamento estratégico adotadas no Instituto: “Teoricamente as etapas do planejamento são aquelas, quem você é, onde você quer chegar, a segunda etapa o IFB trabalha, tem estabelecida essa missão no IFB, depois tem a questão da implantação, ele tem a visão e quer saber o 
que fazer para chegar lá, se é missão do IFB oferecer educação técnica profissional e tecnológica ele tem todo um planejamento para chegar até lá, isso é estabelecido na questão do PDI". Essa fala corrobora com Vasconcellos (2000) na medida em que o planejamento da escola deve envolver tanto a dimensão pedagógica quanto a comunitária e administrativa.

Deste modo, conforme a figura 1 apresenta a definição de missão e visão, como etapa inicial do Planejamento Estratégico no IFB para em seguida realizar o diagnóstico organizacional. A definição da identidade institucional permite responder a uma orientação legal no procedimento elaboração do PDI. Neste contexto, afirma o entrevistado E-09 que a "elaboração do PDI por essas instituições de ensino superior, ela coloca ali que tenha um capítulo de planejamento estratégico onde fique evidenciado a missão, a visão da instituição."

Figura 1 - Macroprocesso de Planejamento estratégico do IFB

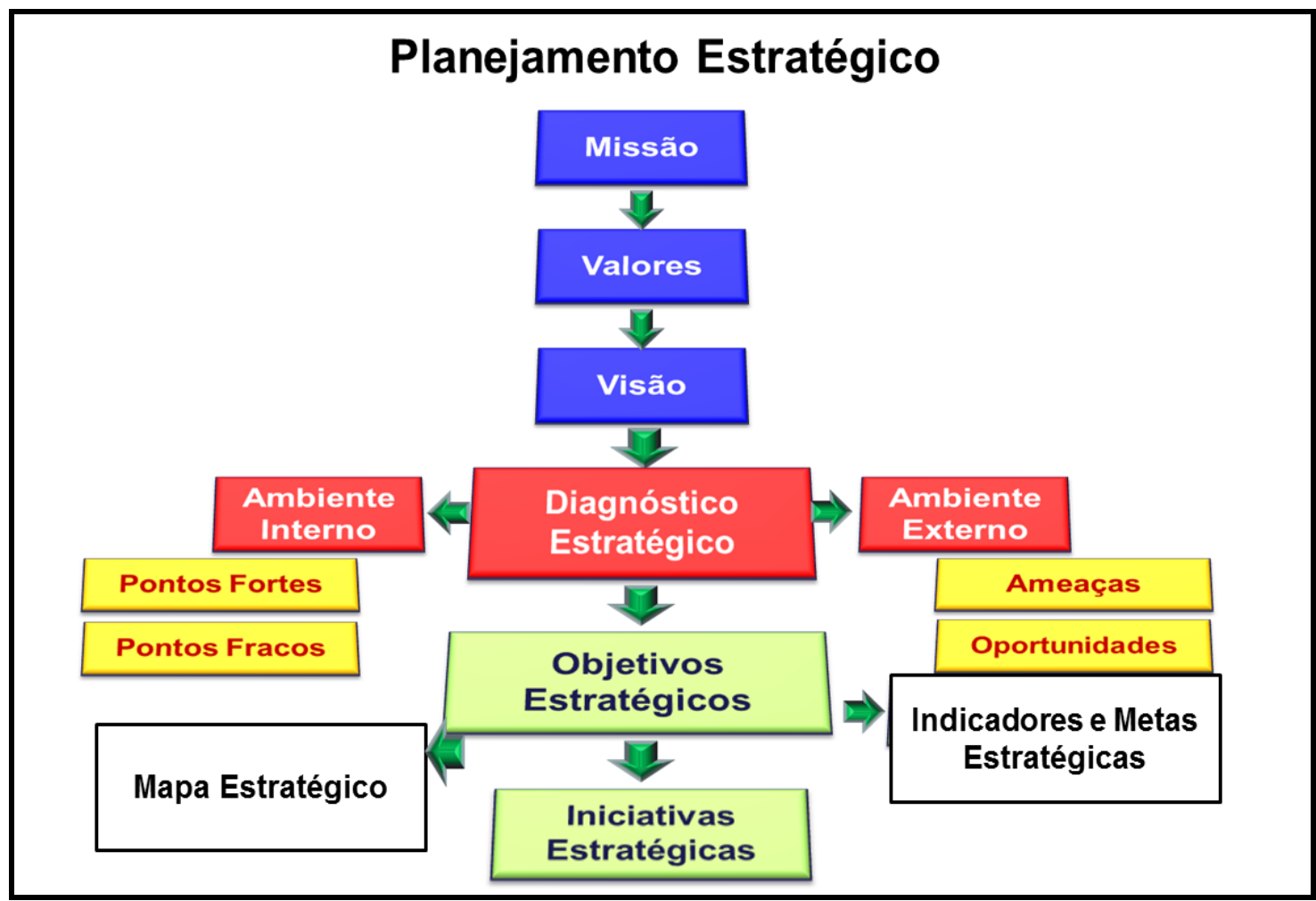

Fonte: (BRASIL, PDI, 2014-2018)

Porém o Plano de Desenvolvimento Institucional do IFB, 2014 a 2018, destaca que "a [missão] de uma organização não se trata apenas de uma frase de efeito, destinada a ornamentar salas, num cartaz, procura-se determinar qual o negócio da organização, por que ela existe, ou ainda, em que tipos de atividades deverão concentrar-se no futuro" (BRASIL, 2014, p. 19). 
Assim é possível inferir que é o ponto de partida que identifica a organização, proporciona alinhamento de forças, comunica os agentes internos e externos, como também apresentado na figura 1 .

Também é importante perceber que mesmo registrando os jargões das teorias administrativas nessa frase e a obrigatoriedade de atender os preceitos legais é evidente a preocupação a Instituição, ao fazer esse registro no PDI, evidenciar o que Veiga (2008) observa sobre como deve ser o projeto de instituições educacionais "É um instrumento que visa orientar os desafios do futuro, o futuro não está dado, não é algo pronto. É preciso entender que o projeto é caracterizado como uma ação consciente e organizada". Por isso, tanto o PDI como o PPI têm a missão como componente imprescindível.

Entretanto, o entrevistado de E-01 ressalta que "A sociedade demanda muito desses institutos [...], e educação é parte da nossa missão, ela é o veículo, e o meio pelo qual a gente faz a transformação, [...] então a nação como um todo quer mais educação". Tudo isso, faz com que "a população cobre resultado, [...] a população tem pressa", tal como ressalta Araújo (1996), que para efetivação do planejamento estratégico na universidade o dificultador é a falta de clareza sobre a missão.

Assim, considerando que a Rede Federal de Educação Profissional desde sua criação em 2008 até o contexto atual expandiu-se abruptamente, como se pode notar no caso do IFB, que passou de uma instituição com apenas um campus para dez campi em menos de uma década de existência.

Esse crescimento acelerado e repentino represou a participação coletiva em certos momentos do processo de gestão. Isto é evidenciado na entrevista de E-01 "Se eu cresço muito rapidamente não a tempo de eu incorporar em mim a missão, porque as coisas acontecem primeiro no nível cognitivo, depois elas acontecem no nível operacional”.

Por outro lado, quanto à importância desses referenciais, ressalta a entrevista E02 "Percebo que as Unidades não têm o mínimo, que seria estampado na sua parede, Missão, Visão e Valores", além disso, "Muitas pessoas participaram do planejamento estratégico da criação do PDI, mas têm muitos servidores novos, eles não foram, digamos assim, ambientalizados em relação a missão, a visão e os valores do Instituto com relação ao que ele pretende ser [a visão]", tal como observa entrevista E-12: "Muita gente não sabe qual a missão do instituto, tem muita gente que não sabe, e 
assim, você não vê no instituto, isso é uma crítica, onde está missão? Eu acho que tinha que ter em todo o lugar(...) que a pessoa vai lá ela vai ler (...)”.

Todavia, as entrevistas de E-1, E-2, E-9 e E-12, reconhecem a importância de se ter uma declaração da identidade institucional, ao mesmo tempo em que apontam fragilidades que podem prejudicar os resultados do IFB. A partir dos enunciados possibilita inferir que na elaboração do Planejamento Estratégico, há necessidade fortalecer ações que viabilize a participação dos servidores com relação à missão, à visão e aos valores; maior envolvimento da comunidade acadêmica; e, que mais servidores deveriam se apropriar da missão institucional.

Essas colocações são significativas no âmbito do Planejamento em instituições educacionais conforme argumentam Fonseca, Nascimento e Silva (1995) que distinguir a participação como um valor e tornando a incapacidade de participação como um desafio a ser superado também é uma tarefa educativa. Isso fica evidente na fala do entrevistado E-1:

[...] então esse tempo necessário para a síntese da missão interna corporis eu acho que é o nosso maior desafio hoje, (...) e que todos nós tenhamos a visão clara de como a gente vai responder a sociedade, e aí que o planejamento estratégico se faz realmente necessário, porque quando todos conhecem as demandas, todos sabem aonde a gente quer chegar, todos podem somar para a gente chegar lá.

Dessa forma, o planejamento estratégico de uma instituição educacional, pública e gratuita, objetiva-se otimizar o desenvolvimento de processos, técnicas e atitudes, para melhorar a gestão e assim garantir a qualidade do serviço oferecido à sociedade, como também desencadear uma reflexão coletiva que promove a adoção de uma prática educativa (VEIGA, 2010).

\section{A inter-relação do Plano de Desenvolvimento Institucional e o Projeto Político Pedagógico}

A elaboração do Plano de Desenvolvimento Institucional é uma exigência às instituições que oferecem Ensino Superior, conforme Decreto n. 5.773, de 9 de maio de 2006. Esse decreto estabelece a necessidade de formulação desse documento a cada cinco anos. Para Otani, Helou e Michels (2011) o PDI se configura como um documento alinhado à construção da identidade institucional atendendo a aspectos operacionais e absorvendo as ações estratégicas descritas no planejamento estratégico 
da instituição. Veiga (2011) acrescenta que esse plano consiste no compromisso não só com o Ministério da Educação e Cultura - MEC - mas também na implementação dos cursos superiores assegurando critérios e padrões de qualidade.

A literatura destaca que o PDI em IES é um instrumento de planejamento estratégico que consiste em orientar as ações de gestores (SEGENREICH, 2005; MIZAEL et al. 2011) sendo uma ferramenta de gestão para aferição da qualidade da administração, argumenta Falqueto (2012). Observa Veiga (2011) que o PDI é uma ferramenta orientada à regulação e à manutenção do estabelecido nos numerosos instrumentos legais, tal como busca compreender que a educação superior busque novos caminhos propondo alternativas para a visão reformista da educação incorporando e transformando-os em projetos pedagógicos.

Para isso o IFB considerou na elaboração de sua metodologia de elaboração do PDI os fundamentos da gestão democrática, determinados tanto para a educação básica quanto para o ensino superior.

Importante ressaltar, no âmbito da gestão democrática, é que está se configura com a participação efetiva de todos os segmentos da comunidade acadêmica no cotidiano da instituição e, especialmente, nos momentos de tomadas de decisões. Dessa forma é imprescindível que representantes de Técnicos, Docentes e Discentes participem da elaboração do PDI, dentro do escopo de sua atuação, haja vista que esta é uma ferramenta norteadora das decisões macro de desenvolvimento institucional. Entrevistado E-8.

Consoante a literatura, documentos institucionais evidenciam a vinculação do PDI ao planejamento. O PDI do IFB foi construído para um horizonte de 5(cinco) anos, 2014 até 2018, em sua apresentação, aponta que as pessoas acreditam que o Plano de Desenvolvimento Institucional é uma peça de planejamento institucional que permite aos gestores saber exatamente o que fazer, quando fazer e como que proporciona acompanhar o desenvolvimento da organização, constituindo um instrumento de gestão.

Assim sendo, ao primar e promover o envolvimento de todos os segmentos da comunidade acadêmica, a instituição caminha em busca de inovação fundada na concepção emancipatória que exige um trabalho constante de elaboração conceitual e de reflexão, como apontado Veiga (2011).

Contudo, verbalizações apresentam a relação entre si, conforme entrevista E-01 “As pessoas, em geral, têm o PDI que é o resultado final desse planejamento como um documento de prateleira, e não como um documento de consulta diária", ao passo que 
Entrevistado E-16 "essa política começa no plano de desenvolvimento institucional, PDI, seria o argumento mais significativo em termos de planejamento no âmbito do instituto". Destaca-se também a verbalização da entrevista E-09:

O PDI que é uma peça obrigatória para nós instituição de ensino superior, que oferta ensino superior, ele é um plano que contempla muito mais do que a definição de um planejamento estratégico, ..., é algo maior. " (...) já que o PDI pede, a missão, a visão, quais são os objetivos e quais são as metas da instituição, a gente fez algo mais, fez o planejamento estratégico dentro dele[PDI], o planejamento institucional que esse é focado no desenvolvimento da instituição enxergamos ele como o desenvolvimento.

Já o PPI, "trata-se de uma projeção dos valores originados da identidade da instituição, materializados no seu fazer específico, cuja natureza consiste em lidar com seu conhecimento, e que deve linear seu horizonte de longo prazo, não se limitando, portanto a um período de gestão. ” (p.35), conforme diretrizes apresentadas pelo Ministério da Educação, por meio do Instituto Nacional de Estudos e Pesquisas Educacionais Anísio Teixeira - INEP.

Pacheco (2001) apresenta os fundamentos da proposta pedagógica para os Institutos Federais destacando que essa deve recusar o conhecimento enciclopédico e primar pelo pensamento analítico na compreensão do mundo do trabalho e que possibilite uma participação qualitativa nele, destaca que isso também é valido tanto para engenharias quanto para licenciaturas.

No IFB, em 2012 aprovou Resolução por sua instância máxima, mas esse documento diverge do que está posto dentro do Plano de Desenvolvimento Institucional. No entanto, há o compromisso de revisão como expresso: "Esses princípios são observados e detalhados no PPI, o qual deverá ser objeto de revisão anual, por comissão instituída para este fim. ” (BRASIL, PDI 2014-2018),

Assim ambos os documentos norteiam as ações de gestores e servidores e permeia o processo decisório da instituição, conforme aponta as entrevistas: E-5 "É muito claro o planejamento [estratégico] aqui do instituto, ele é feito com antecedência e baseado em um Documento, PDI, um documento norteador que define as estratégias a serem traçadas de modo a se atingir aqueles objetivos traçados do PDI", e E-18 acrescenta “(...) um outro instrumento norteador, que é o nosso Projeto Político Institucional". 


\section{PDI, PPI e a Relação com Planejamento Estratégico}

A relação entre PDI, PPI e Planejamento Estratégico, evidencia a posição de importância em que o PDI ocupa dentro de instituições de ensino superior, além da relação direta com o planejamento estratégico, apoia a gestão, alinha ações que se vincula ao processo de avaliação institucional, como determinado no decreto de regulamentação, promove impacto direto no processo de desenvolvimento e expansão, bem como, permite que a IES assuma sua posição no processo de construção e transferência de conhecimento, articulando ações na perspectiva da indissociabilidade entre ensino, pesquisa, extensão e gestão.

Os enunciados apresentados que trazem o PDI e Planejamento Estratégico evidenciam, no mínimo, a relação intrincada e complexa entre os termos. Tanto, observam-se nas verbalizações e documentos, as percepções ora convergente e divergente sobre qual a posição que ocupa o Planejamento Estratégico frente ao PDI na Instituição.

Todavia, o PDI, pela sua constituição e finalidade é um instrumento estratégico da organização. Portanto, infere-se que o PDI pode constitui-se instrumento de Planejamento Estratégico nas Instituições Federais de Ensino Superior, confirmando o conceito proposto por Segenreich (2005).

Nesse contexto, é possível perceber que o PDI é um documento amplo, que sistematiza o planejamento estratégico e se vincula ao PPI. Dessa forma, afirma entrevista E-2 "Então nós temos lá o PDI, que é uma ferramenta de planejamento extremamente importante e integrado ao que foi definido no PPI". Do mesmo modo, quanto sua importância no contexto organizacional o Planejamento Estratégico não só apoia o desenvolvimento institucional, como, proporciona a construção de uma escola de referência com uma educação de qualidade.

Entretanto, na aferição de resultados organizacionais, busca-se analisar se há elementos concretos que revelam a relação entre as intenções e propósitos das IES expressos em documentos como PPI, PDI entre outros norteadores (planejamento estratégico), em relação às ações e práticas institucionais de forma a observar se estes elementos são percebidos, desejados e construídos pelos atores internos, além de identificados pela comunidade externa.

Para Marcelino (2004) o planejamento estratégico fornece inputs para implementação, monitoramento e controle para o Plano de Desenvolvimento 
Institucional - PDI. Cabe ressaltar que, para este estudo adota-se o pensamento de que “o planejamento estratégico é o mesmo que planejamento, mas com ênfase no aspecto de longo prazo dos objetivos, e na análise global do cenário" conforme (MATIASPEREIRA, 2010, p. 115).

O PDI se evidencia como direcionador dos esforços e ações estratégicas organizacionais, utilizando para isso ferramentas de planejamento e gestão. Neste contexto, confunde-se o PDI, sendo o próprio planejamento estratégico da organização, mas, esse não mais como documento auxiliar ou adjacente, mas, sim, revestido com pensamentos e características tanto para o desenvolvimento da organização, quanto para alcance de objetivo e metas.

É possível afirmar, segundo Silva (2008), que é complexo conceber os aspectos que diferenciam o Planejamento Estratégico do Plano de Desenvolvimento Institucional. A fala na entrevista E-09 evidencia esta relação como peça diferente, divergindo Segenreich (2005) e Mizael et al (2011) e convergindo com Marcelino (2004) quando afirma que o PDI é um documento auxiliar ao Planejamento Estratégico.

[...] então o planejamento estratégico do IFB ele é uma peça que poderia estar fora, mas a gente achou melhor caminharmos junto com o PDI então, por isso que o planejamento estratégico do IFB está dentro do PDI, porém enxergamos como peças diferentes, temos um Plano de Desenvolvimento da Instituição e temos um Planejamento Estratégico e Planejamento Institucional. Entrevistado E-09.

De acordo com Francisco et al (2011), apesar das discussões sobre a posição estratégica do PDI e suas relações com o planejamento estratégico, ambos podem estar diretamente vinculados, tal como ressalta Mizael et al (2011), que o PDI não deve apenas repousar sob critério de credenciamento, recredenciamento, mas, sim, de planejamento estratégico.

Para Santos (2008), o PDI norteia a proposta pedagógica da instituição em uma perspectiva plurianual, desenvolvendo o projeto institucional de acordo com uma proposta objetiva, funcional e determinante aos intentos estratégicos da instituição, ao passo que Otani, Helou e Michels (2011), afirmam que fornecem um indicativo de eficácia institucional e pedagógica, além de que o PDI apresenta um retrato concreto sobre a consecução das ações estratégicas elencadas no decurso do Planejamento Estratégico da Instituição.

Observa-se, também, a necessidade em integrar PDI, PPI e planejamento, conforme verbalização da entrevista E-4, "Nós temos que construir nossas próprias 
metas e aí tem que melhorar o diálogo do Planejamento Estratégico entre PDI e PPI, esse diálogo tem que ser melhorado, e esse diálogo vai ser melhorado a partir de clareza da função social, da missão”. Da mesma forma, ressalta E-16 “(...) e aí ele traça um conjunto de direcionamentos estratégicos no âmbito institucional para atender ao que essa política pública pede, então a gente vê o PDI, Projeto Político Pedagógico, planejamento anual, e aí a implementação acontece”.

\section{Considerações Finais}

O PDI, PPI e Planejamento estratégico no Instituto Federal de Brasília, se interrelacionam, interagem em decorrência da natureza dinâmica que envolve o processo que contribuem para a eficácia organizacional.

Com base nos resultados desta pesquisa, o planejamento estratégico é integrado ao PDI no IFB. Esse documento de fundamento legal é o mais abrangente da Instituição, o qual aponta para diretrizes estratégicas institucionais e educacionais tanto para o ensino, pesquisa, extensão e gestão. Assim, sendo, o PDI por si só, não é executável, e, para isso, alinham o PPI e Planejamento Estratégico de forma a operacionalizar-se.

A ferramenta de Planejamento Estratégico integrado ou não ao PDI e PPI, temse mostrado útil e adequado ao IFB, para o alcance da eficácia da organização. As dificuldades e necessidade de ajustes e atualizações sempre estarão presentes, ainda mais, em organizações dinâmicas e complexas. As soluções para resolvê-las não podem ser emprestadas, mas, sim, encontradas, discutidas e disseminadas interna corpus.

Portanto, a integração eficiente entre PDI, PPI e Planejamento Estratégico, além de comunicar a missão, objetivos e metas institucionais, corroboram na construção de uma instituição de referência com a educação de qualidade, afirmando sua função social, orientando a ação dos servidores e gestores.

\section{REFERÊNCIAS}

ARAÚJO, M. A. D. Planejamento estratégico: um instrumental à disposição das universidades? Revista de Administração Pública, Rio de Janeiro, FGV, n.30, p. 7486, jul./ago. 1996. 
BRASIL. Decreto n' 5773, de 9 de maio de 2006. Disponível em: <http://www.planalto.gov.br/ccivil_03/_ato2004-2006/2006/Decreto/D5773.htm>. Acesso em: 10 abr. 2015.

Instituto Nacional de Estudos e Pesquisas Educacionais Anísio Teixeira INEP. Avaliação externa de Instituições de Educação Superior: Diretrizes e Instrumentos. Disponível em:

<http://www.publicacoes.inep.gov.br/portal/download/436>. Acesso em: 10 abr. 2015.

Plano de Desenvolvimento Institucional: PDI 2014-2018. Instituto Federal de Brasília. Acesso em 03 jan 2016. Disponível em:

<http://www.ifb.edu.br/attachments/article/3933/Plano_de_Desenvolvimento_Institucio nal_2014_2018_IFB.pdf>. Acesso em: 03 jan. 2016.

CRESWELL, J.W. Projeto de pesquisa: métodos qualitativo, quantitativo e misto. Trad. Luciana de Oliveira da Rocha. Porto Alegre: Artmed, 2007.

DAL MAGRO, C.B.; RAUSCH, R.B. Plano de Desenvolvimento Institucional de Universidades Federais Brasileiras. Administração, ensino e pesquisa, RJ, v. 13 n. 3 , p. 427-454, jul/ago. set. 2012.

FALKEMBACH, E. M. F. Planejamento Participativo: uma maneira de pensa-lo e encaminhá-lo com base na escola. In. VEIGA. I. P. A. Projeto Político Pedagógico da Escola: uma construção possível. Campinas, SP: Papirus, 2010.

FALQUETO, J. M. Z. A Implantação do planejamento estratégico em universidades: O Caso da Universidade de Brasília. 191 f. Dissertação (Mestrado em Administração Pública) - Universidade de Brasília, Brasília, 2012.

FORPLAD. Fórum dos Pró-Reitores de Planejamento e Administração das Instituições Federais. Planejamento Estratégico em Instituições Federais de ensino superior: proposta de processo participativo, dez. 1995.

FRANCISCO, T. H. A.; et al. O impacto da estrutur, legal do PDI no processo de planejamento estratégico de instituições do sistema AMPESC. Revista Gual, Edição Especial, p.133-162, 2011.

FRANCO, M. L. P. B. Análise de conteúdo. Brasília: Plano, 2003.

MARCELINO, G. F. Planejamento estratégico no setor público: uma experiência no Palácio do Planalto. Revista do Serviço Público. v. 53, n. 4, p. 107-124, 2002.

MARCELINO, G. F. (Org.). Gestão estratégica de universidade. $1^{\text {a }}$ ed. Brasília: Editora UnB, 2004.

MATIAS-PEREIRA, J. Manual de gestão pública contemporânea. $3^{a}$ ed. São Paulo: Editora Atlas S.A. 2010. 
MEYER JR., V. Planejamento universitário: ato racional, político ou simbólico - um estudo de universidades brasileiras. Alcance (UNIVALI), Itajaí, v. 12, n. 3. p. 373-389, 2005.

MINTZBERG, H. The fall and rise of strategic planning. Harvard Business Review, v. 72, n. 1, p. 107-114, 1994.

MINTZBERG, H.; AHLSTRAND, B.; LAMPEL, J. Safári de estratégia: um roteiro pela selva do Planejamento Estratégico. Porto Alegre: Editora Bookman. $2^{\mathrm{a}}$ ed. 2010.

MIZAEL, G. A.; et al. Análise do Plano de Desenvolvimento Institucional das universidades federais do Consórcio Sul-Sudeste de Minas Gerais. Revista de Administração Pública, vol.47, n.5, p. 1145-1164, 2013.

OTANI, N; HELOU, A. R. H. A; MICHELS, E. Diferenças entre o PDI e o planejamento estratégico na percepção dos PIs de IES do segmento privado não universitário. XI Colóquio Internacional sobre Gestão Universitária na América do Sul. Florianópolis, 2011.

PACHECO. E (org.). Institutos Federais: uma revolução na educação profissional e tecnológica. São Paulo, Editora Moderna, 2011.

SEGENREICH, S. C. D. O PDI como referente para avaliação de Instituições de Educação Superior: lições de uma experiência. Ensaio, Rio de Janeiro, v. 13, n. 47, p. 149-168, abr./jun. 2005.

SILVA, G. J. C. O ensino superior privado: o confronto entre lucro, expansão e qualidade. 2008. 282f. Tese (Doutorado). Programa de Pós-Graduação em Ciências Sociais. Universidade de Brasília. Brasília, 2008.

VASCONCELLOS, C. S. Planejamento projeto de ensino: aprendizagem e projeto político-pedagógico. Ladermos Libertad-1. $7^{\circ}$ ed. São Paulo, 2000.

VEIGA, I. P. A. FONSECA, M. (orgs.). As dimensões do projeto políticopedagógico. Campinas, SP: Papirus, 2001.

VEIGA, I. P. A. Projeto político-pedagógico da escola: uma construção possível. Papirus. $6^{\text {a }}$ ed. Campinas, SP, 2011.

VEIGA, I. P. A. Educação básica e educação superior: projeto político pedagógico. Papirus. 6 ${ }^{\mathrm{a}}$ ed. Campinas, SP, 2011. 


\section{Como referenciar este artigo}

DIAS, P. H. R. C; SOUSA, J. C; VIEIRA, C. C. F. Estratégia Institucional: relação entre o PDI, PPI e Planejamento Estratégico no IFB. Revista on line de Política e Gestão Educacional, Araraquara, v.21, n.2, p. 334-348, maio-ago. 2017. Disponível em: <http://dx.doi.org/10.22633/rpge.v21.n.2.2017.10069>. ISSN: 1519-9029.

Submetido em: 06/07/2017

Aprovado em: 09/07/2017 